\title{
PA-144 ACTIVE PHARMACOVIGILANCE IN CôTE D'IVOIRE
}

Mariam Mama Djima. Institut Pasteur, Côte d'Ivoire

10.1136/bmjgh-2016-000260.170

Background In Africa, pharmacovigilance (PV) is a relatively new science. Yet the African context is favourable to the irrational use of medicines, the circulation of counterfeit drugs, and a high consumption of traditional medicine. This should make PV in African countries a critical and crucial issue to ensure the safe use of treatments available. The collection system used in pharmacovigilance in Africa is predominantly passive. This passive system suffers from significant underreporting because it detects only $1-10 \%$ of adverse events. The limit in the passive detection and the growing concerns about security in the long term of drugs widely used in health programs, have stimulated in many countries the implementation of active systems such as actively seeking to improve the development of PV in their countries. In Côte d'Ivoire, pharmacovigilance at the regulatory level started in 1988. What is actually the state of pharmacovigilance and the impact of active research in the development of pharmacovigilance?

Methods This is an observational descriptive study using a qualitative analysis of interviews in order to provide answers to these questions. The interview guides are constructed from a questionnaire already used in the monitoring of pharmacovigilance activities by the Uppsala Monitoring Center in countries with limited resources.

Results Active surveillance has several sources. A well-known source is the pharmaceutical industry in the conduct of clinical 
trials and the risk management plans. The pharmaceutical industry accounts for over $80 \%$ of reports of adverse effects at national level. The second data source are research centres, but the reporting of adverse effects is not made at national level. The last source of data comes from active operational research studies which as a source are weak and this should be strengthened.

Conclusions Active pharmacovigilance is to be encouraged in Côte d'Ivoire because it will collect data to improve the safety of medicines consumed by the population. 